\title{
Combined use of preoperative lymphocyte counts and the post/ preoperative lymphocyte count ratio as a prognostic marker of recurrence after curative resection of stage II colon cancer
}

\author{
Seiichi Shinji ${ }^{1}$, Yoshibumi Ueda ${ }^{2,3}$, Takeshi Yamada ${ }^{1}$, Michihiro Koizumi ${ }^{1}$, Yasuyuki \\ Yokoyama $^{1}$, Goro Takahashi ${ }^{1}$, Masahiro Hotta ${ }^{1}$, Takuma Iwai ${ }^{1}$, Keisuke Hara ${ }^{1}$, \\ Kohki Takeda ${ }^{1}$, Mikihiro Okusa ${ }^{1}$, Hayato Kan ${ }^{1}$ and Eiji Uchida ${ }^{1}$ \\ ${ }^{1}$ Department of Gastrointestinal and Hepato-Biliary-Pancreatic Surgery, Nippon Medical School, Tokyo, Japan \\ ${ }^{2}$ Graduate School of Arts and Sciences, The University of Tokyo, Tokyo, Japan \\ ${ }^{3}$ AMED-PRIME, Japan Agency for Medical Research and Development, Tokyo, Japan \\ Correspondence to: Seiichi Shinji, email: s-shinji@nms.ac.jp \\ Keywords: lymphocyte count; post/preoperative lymphocyte count ratio; colon cancer; prognostic marker; stage II \\ Received: August 21,2017 Accepted: December 11,2017 Published: December 20, 2017 \\ Copyright: Shinji et al. This is an open-access article distributed under the terms of the Creative Commons Attribution License 3.0 \\ (CC BY 3.0), which permits unrestricted use, distribution, and reproduction in any medium, provided the original author and source \\ are credited.
}

\section{ABSTRACT}

Purpose: Diagnostic markers for recurrence of colorectal cancer have not been established. The aim of the present study was to identify new diagnostic markers for recurrence after curative surgery of stage II colon cancer.

Materials and Methods: In this study, the prognostic values of the preoperative lymphocyte count and the post/preoperative lymphocyte count ratio (PPLR) were evaluated in 142 patients with localized colon cancer treated with surgery at a single medical center. The associations of patient demographics, blood chemistry, and serum biochemical indices with recurrence-free survival (RFS) and cancer-specific survival (CSS) were examined by univariate and multivariate analyses.

Results: Receiver operating characteristic (ROC) curve analysis showed that the optimal cut-off values of the lymphocyte count and PPLR were, respectively, 1555.2/ $\mu l$ and 1.151 for RFS. On univariate analysis, tumor depth of invasion, carbohydrate antigen 19-9 (CA19-9), and preoperative low lymphocyte count $(\leq 1555.2 / \mu \mathrm{l})$ were all correlated with poorer RFS $(p<0.05)$. On multivariate analysis, T4, low lymphocyte count, and low PPLR were independent predictors of poor RFS. Furthermore, the patients were categorized into four categories based on preoperative lymphocyte count high/low and PPLR high/low. Patients with a low preoperative lymphocyte count and low PPLR had the poorest RFS and CSS compared to the other patients.

Conclusion: The combination of the preoperative lymphocyte count and the PPLR appears to be a potential marker for predicting recurrence of stage II colon cancer.

\section{INTRODUCTION}

Colorectal cancer (CRC) is the third most commonly diagnosed malignancy, the fourth leading cause of cancerrelated deaths worldwide [1], and the second most common cause of cancer-related death in Japan [2]. During the past two decades, advances in chemotherapy protocols have drastically decreased the risk of cancer recurrence and improved overall survival time of patients with stages III and IV [3-8]. On the other hand, use of chemotherapy among patients with stage II colon cancer is controversial $[9,10]$, as is the usefulness of adjuvant chemotherapy after 
surgery. Therefore, better prognostic markers are needed to improve the outcomes of patients with CRC.

Currently, several predictors for recurrence of curatively resected CRCs have been proposed. For instance, carcinoembryonic antigen (CEA) is a prognostic marker for long-term CRC recurrence [11, 12]. Additionally, the hemogram of the peripheral blood could be a useful diagnostic marker. For instance, the lymphocyte count $[13,14]$, the systemic inflammation score (SIS) [15], the lymphocyte and monocyte ratio (LMR) [16], the neutrophil and lymphocyte ratio (NLR) [17], the platelet to lymphocyte ratio (PLR) [18], and the platelet distribution width (PDW) [17] have been reported to be correlated with disease-free survival (DFS) and overall survival (OS) in patients with CRC. However, according to the European Group on Tumor Markers (EGTM) published guidelines, CEA is more useful for postoperative surveillance than as a predictor of recurrence [19]. Other predictors have been emerging over the last several years, and they are not yet practically useful. Therefore, more potential prognostic markers are required. In the present study, the aim was to identify other prognostic markers for CRC, and it was found that combined use of the lymphocyte count and the post/preoperative lymphocyte count ratio (PPLR) was an effective prognostic marker.

\section{RESULTS}

\section{Patients' characteristics}

A total of 142 patients with Stage II colon cancer who underwent curative surgery in our hospital between January 2008 and December 2014 were enrolled in the study (Figure 1). The male to female ratio was around 1.3: 1. The mean age at the time of diagnosis was 72 years (range, 43 to 94 years). In the present study cohort, 17 patients $(12.0 \%)$ developed tumor recurrence during the follow-up period. Among them, including overlaps, 4 patients showed local recurrence, 5 patients had peritoneal metastases, 5 patients had liver metastases, 4 patients had lung metastases, and 1 had brain metastasis. Five patients $(3.5 \%)$ died from cancer recurrence. Laboratory results, including various blood cell counts, are shown in Table 1. The median follow-up duration was 47.0 months (range, 6.1 to 116.3 months).

\section{ROC curve analysis}

Applying receiver operating characteristic (ROC) curve analysis, the cut-off value for the lymphocyte count for RFS was $1555.2 / \mu 1$, and the area under the curve

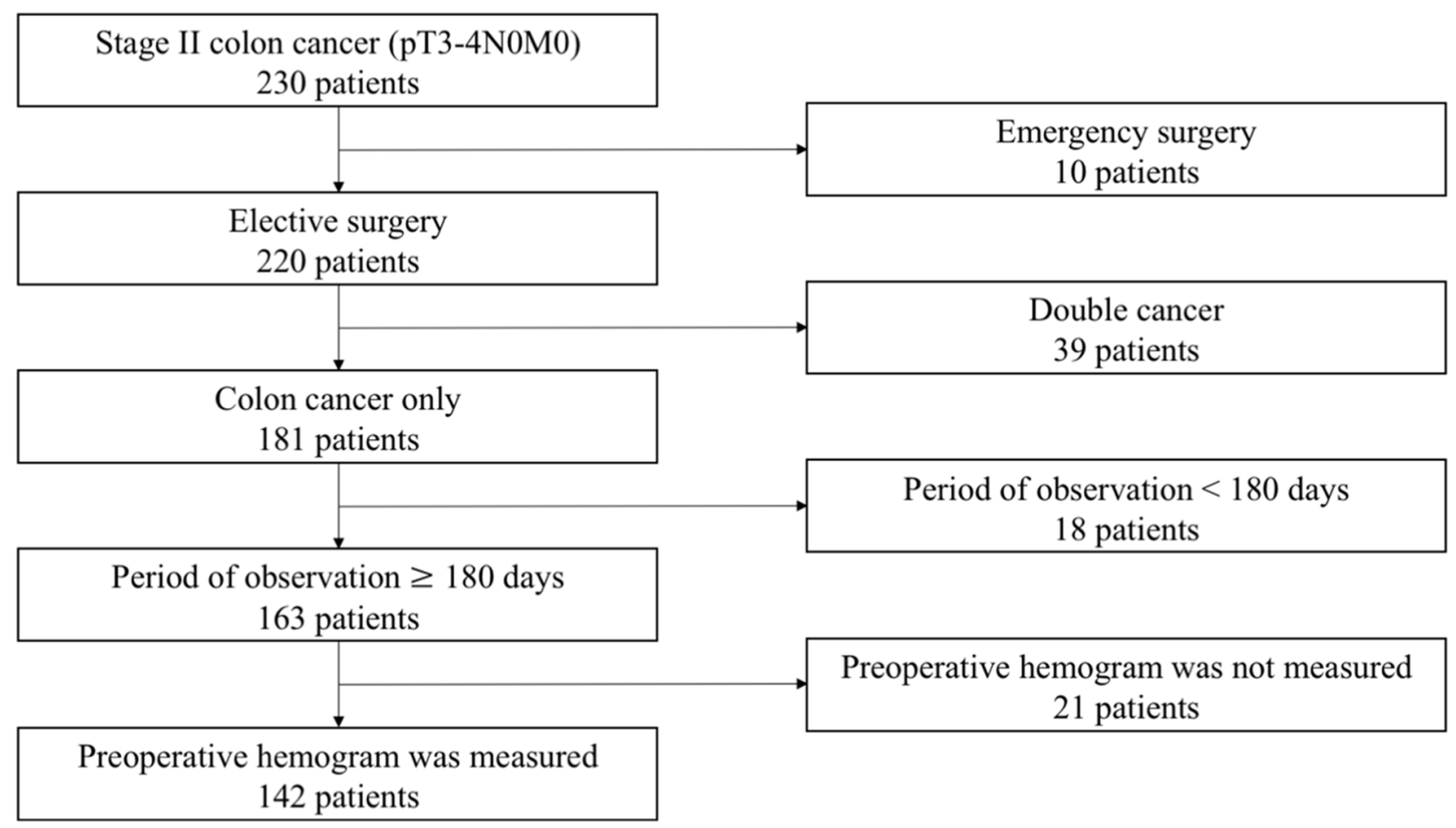

Figure 1: Flow chart of the 230 patients enrolled in this study. 
Table 1: Patients' baseline demographic and clinical characteristics

\begin{tabular}{|c|c|c|}
\hline Parameter & & Patients $(n=142)$ \\
\hline \multirow[t]{2}{*}{ Age (y) } & $<60$ & $16(11.3)$ \\
\hline & $\geq 60$ & $126(88.7)$ \\
\hline \multirow[t]{2}{*}{ Sex } & $\mathrm{F}$ & $62(43.7)$ \\
\hline & M & $80(56.3)$ \\
\hline \multirow[t]{2}{*}{ Location } & Left & $81(57.0)$ \\
\hline & Right & $61(43.0)$ \\
\hline \multirow[t]{5}{*}{ Differentiation } & Pap & $4(2.8)$ \\
\hline & Well & $54(38.0)$ \\
\hline & Moderately & $76(53.5)$ \\
\hline & Poor & $1(0.7)$ \\
\hline & Muc & $7(4.9)$ \\
\hline \multirow[t]{2}{*}{ Tumor invasion depth } & $\mathrm{T} 3$ & $120(84.5)$ \\
\hline & $\mathrm{T} 4$ & $22(15.5)$ \\
\hline \multirow[t]{2}{*}{ Lymphatic involvement } & Negative & $37(26.1)$ \\
\hline & Positive & 105 (73.9) \\
\hline \multirow[t]{2}{*}{ Venous involvement } & Negative & $39(27.5)$ \\
\hline & Positive & $103(72.5)$ \\
\hline \multirow[t]{2}{*}{ Diameter } & $<5 \mathrm{~cm}$ & $63(45.0)$ \\
\hline & $\geq 5 \mathrm{~cm}$ & $77(55.0)$ \\
\hline \multirow[t]{2}{*}{ CEA } & $<5 \mathrm{ng} / \mathrm{ml}$ & $93(69.4)$ \\
\hline & $\geq 5 \mathrm{ng} / \mathrm{ml}$ & $41(30.6)$ \\
\hline \multirow[t]{2}{*}{ CA19-9 } & $<37 \mathrm{U} / \mathrm{ml}$ & $112(85.5)$ \\
\hline & $\geq 37 \mathrm{U} / \mathrm{ml}$ & $19(14.5)$ \\
\hline Age (y) & & $72.1 \pm 10.8$ \\
\hline WBC count $\left(\times 10^{2} / \mu \mathrm{l}\right)$ & & $66.4 \pm 21.9$ \\
\hline Neutrophil count $\left(\times 10^{2} / \mu \mathrm{l}\right)$ & & $45.0 \pm 20.2$ \\
\hline Lymphocyte count $\left(\times 10^{2} / \mu \mathrm{l}\right)$ & & $15.5 \pm 5.8$ \\
\hline Monocyte count $\left(\times 10^{2} / \mu \mathrm{l}\right)$ & & $4.0 \pm 1.7$ \\
\hline Platelet count $\left(\times 10^{4} / \mu \mathrm{l}\right)$ & & $27.8 \pm 9.7$ \\
\hline Albumin $(\mathrm{g} / \mathrm{dl})$ & & $3.8 \pm 0.6$ \\
\hline \multirow[t]{2}{*}{ Adjuvant chemotherapy } & No & $128(80.1)$ \\
\hline & Yes & $14(9.9)$ \\
\hline
\end{tabular}

(AUC) was 0.61 (95\% confidence interval (CI), 0.4950.728 ), with a sensitivity of $88.2 \%$ and a specificity of $48.8 \%$. For NLR, the optimal cut-off value for RFS was 3.197 , and the AUC was 0.56 (95\% CI, 0.411-0.698), with a sensitivity of $47.1 \%$ and a specificity of $64.0 \%$ (Figure 2 , Table 2). These data suggest that the preoperative lymphocyte count is superior to NLR as a prognostic marker. Furthermore, for PPLR, the optimal cut-off value for RFS was 1.151, and the AUC was 0.51 (95\% CI,
$0.362-0.65)$, with a sensitivity of $64.7 \%$ and a specificity of $41.6 \%$ (Table 2 ).

\section{Recurrence-free survival and cancer-specific survival}

Kaplan-Meier analysis and the log-rank test were used to evaluate differences in RFS between group pairs defined by the lymphocyte count. Patients with a low 
Table 2: Receiver operating characteristic (ROC) curve analyses for recurrence-free survival (RFS)

\begin{tabular}{lccccc}
\hline & AUC & $\mathbf{9 5 \%}$ CI & Sensitivity & Specificity & Cut-off \\
\hline Lymphocyte count & 0.61 & $0.495-0.728$ & $88.2 \%$ & $48.8 \%$ & 1555.2 \\
NLR & 0.56 & $0.411-0.698$ & $47.1 \%$ & $64.0 \%$ & 3.197 \\
PPLR & 0.51 & $0.362-0.65$ & $64.7 \%$ & $41.6 \%$ & 1.151 \\
\hline
\end{tabular}

AUC: area under the curve, CI: confidence interval, NLR: neutrophil and lymphocyte ratio, PPLR: post/preoperative lymphocyte count ratio.

lymphocyte count $(\leq 1555.2 / \mu 1, \mathrm{n}=79)$ had a significantly shorter RFS than those with a high lymphocyte count $(>1555.2 / \mu 1, \mathrm{n}=63)(p=0.00238)$ (Figure 3A). Furthermore, patients with a low lymphocyte count $(\leq 1555.2 / \mu \mathrm{l})$ also had a significantly worse CSS than those with a high lymphocyte count $(p=0.0315)$ (Figure 3B). Table 3 shows the distribution of the clinical background characteristics of the studied patients divided into two groups by the lymphocyte count cut-off of 1555.2/ $\mu 1$. Significant between-group differences were found for recurrence $(p=0.004)$, age $(p=0.003)$, lymphatic involvement $(p=0.036)$, diameter $(p=0.042)$, and WBC count $(p=0.005)$. In the group with a low lymphocyte count $(\leq 1555.2 / \mu \mathrm{l}), 7$ of 79 patients had adjuvant chemotherapy, while 7 of 63 patients had adjuvant chemotherapy in the group with a high lymphocyte count $(>1555.2 / \mu \mathrm{l})$; there was no between-group difference $(p=$ $0.779)$. These data suggest that the lymphocyte count is a predictive marker for CRC recurrence.

\section{Univariate and multivariate analyses for RFS}

In the group with a low lymphocyte count $(\leq 1555.2 /$ $\mu \mathrm{l}), 15$ of 79 patients had recurrences $(19 \%)$, whereas

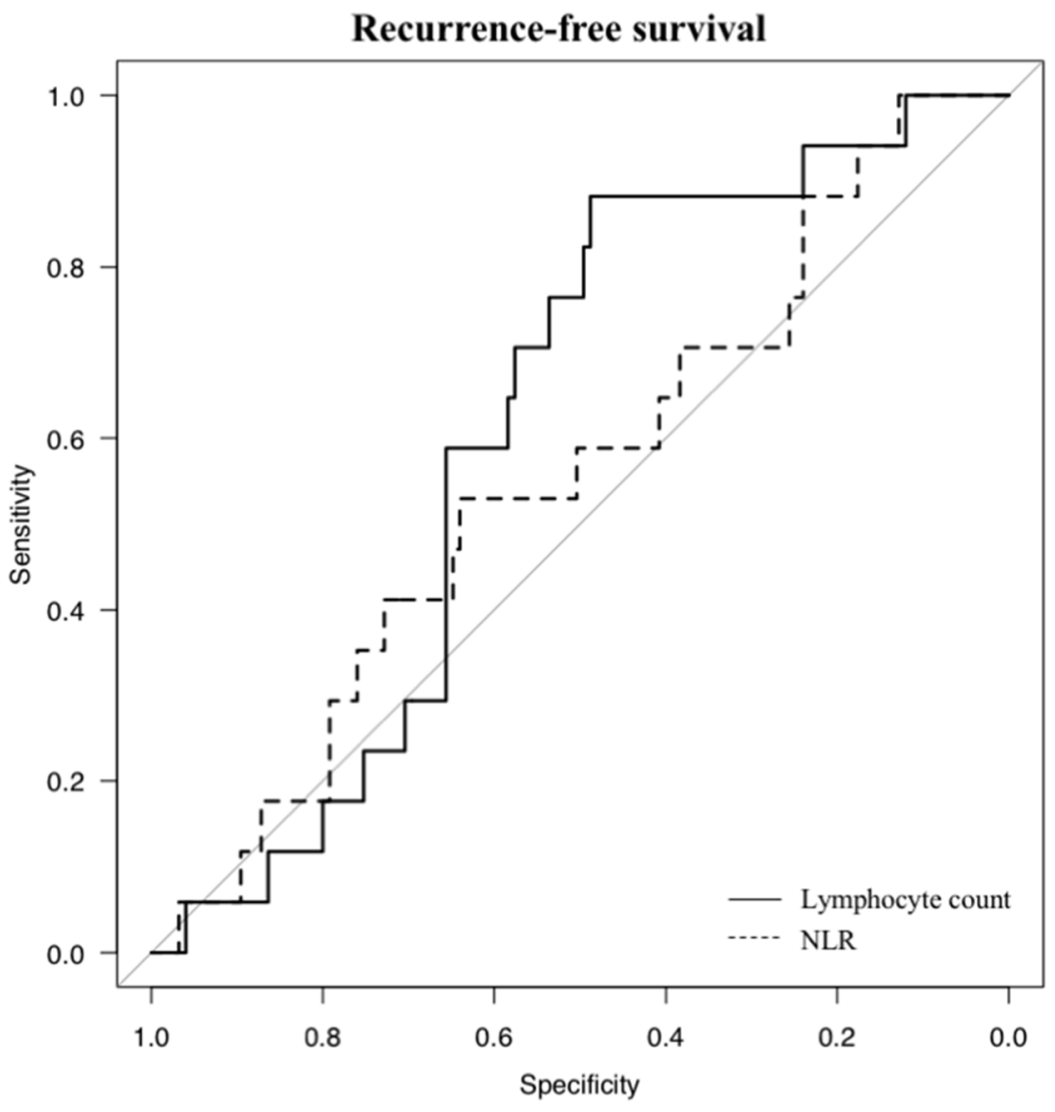

Figure 2: Receiver operating characteristic curve analyses For RFS, the lymphocyte count is represented by the solid line with an area under the curve (AUC) of $0.61(95 \%$ CI, 0.495-0.728), with a sensitivity of 88.2\% and a specificity of $48.8 \%$, and NLR is represented by the dotted line with an AUC of $0.56(95 \% \mathrm{CI}, 0.411-0.698)$, with a sensitivity of $47.1 \%$ and specificity of $64.0 \%$. 
2 of 63 patients had recurrence in the group with a high lymphocyte count $(>1555.2 / \mu 1)(3 \%)(p=0.004)$. Univariate and multivariate analyses were performed to evaluate the relationships between clinical characteristics and patients' outcomes. On univariate analyses, location (right colon vs left colon), tumor depth of invasion (T3 vs T4), CA19-9 (<37 vs $\geq 37 \mathrm{U} / \mathrm{ml})$, lymphocyte count ( $\leq$ $1555.2 / \mu \mathrm{l}$ vs $>1555.2 / \mu \mathrm{l})$, and PPLR $(\leq 1.151 \mathrm{vs}>1.151)$ were all associated with RFS (Table 4). Factors with $p$ values $<0.05$ on univariate analyses were included in the COX multivariate model analysis. On multivariate analysis, T4, a low lymphocyte count $(\leq 1555.2 / \mu 1)$, and low PPLR $(\leq 1.151)$ were independent predictors of poor RFS (Table 5).

\section{Scatter-plot of the preoperative lymphocyte count and the post/preoperative lymphocyte count ratio (PPLR)}

There was a significant negative correlation between the preoperative lymphocyte count and the PPLR (Pearson's product moment correlation coefficient, $r=-0.501,95 \%$ CI: $-0.615-0.366, p<0.01)$. However, the group with a low preoperative lymphocyte count and low PPLR appeared to have more frequent recurrences (Figure 4).

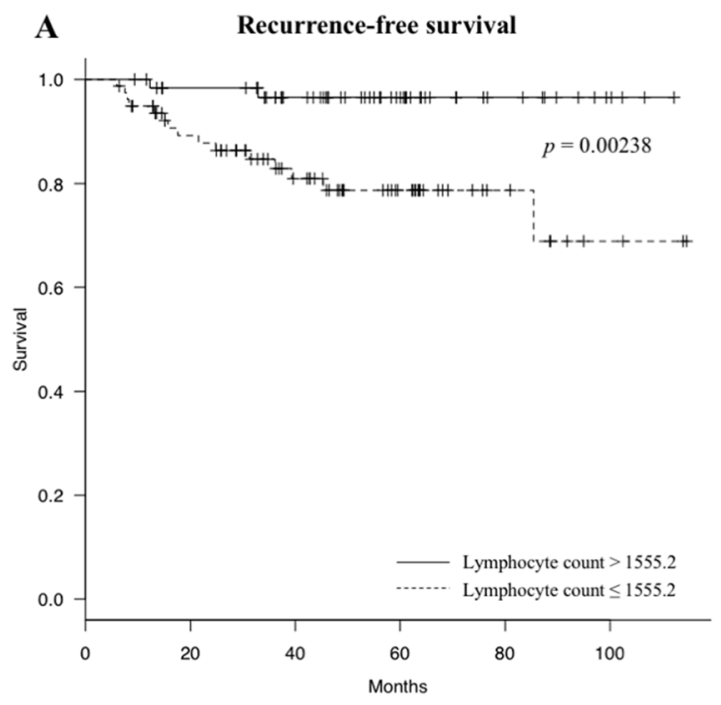

\section{RFS and CSS curves categorized by the preoperative lymphocyte count and the PPLR}

Patients in category 4 had a worse RFS (log-rank $p<0.0001$ ) (Figure 5A) and a worse CSS (log-rank $p=$ 0.00128 ) (Figure 5B) compared to the patients in other three categories. These data suggest that the predictive accuracy for colon cancer recurrence based on lymphocyte number increases in combination with PPLR.

\section{DISCUSSION}

$\mathrm{CRC}$ is one of the most frequent cancers affecting both sexes worldwide. Surgery and adjuvant chemotherapy with an oral uracil and tegafur plus leucovorin (UFT/ UZEL) regimen have become standard therapy for patients with high-risk stage II and stage III colon carcinomas [3]. Nearly $25 \%$ of patients who undergo surgical resection for localized colon cancer will experience disease recurrence [10]. Although retrospective comprehensive studies showed strong associations between genetic mutations and the clinical outcomes of patients with $\mathrm{CRC}$, no validated biomarkers are currently used in routine clinical settings [20]. Recently, components related to immunity have been of interest as diagnostic markers for CRC, including NLR [17] and PDW [17], and these diagnostic markers have a potential for practical use.

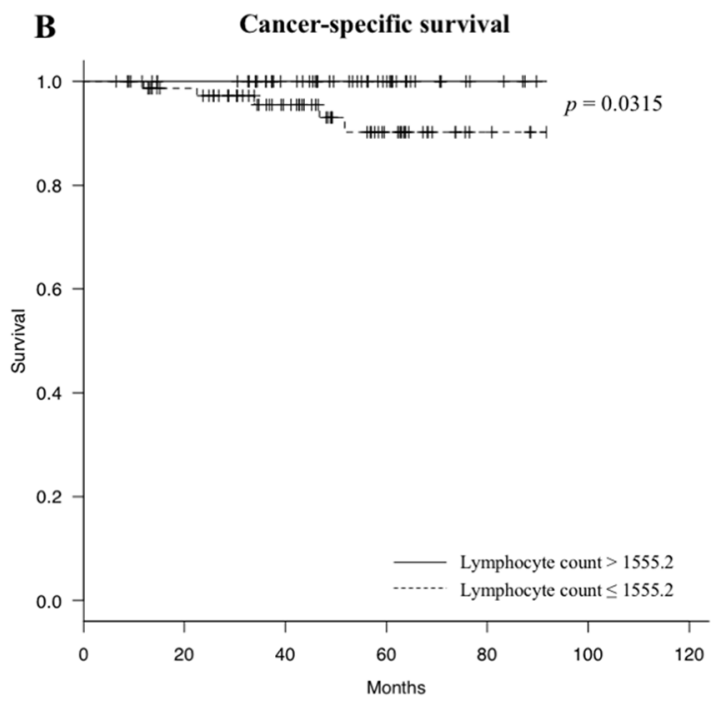

Figure 3: Recurrence-free survival (RFS) and cancer-specific survival (CSS) curves grouped by lymphatic cell count (A) Patients with a low lymphocyte count $\leq 1555.2 / \mu \mathrm{l}$ (dotted line) have a significantly worse RFS compared to patients with a high lymphocyte count ( $>$ $1555.2 / \mu \mathrm{l})$ (solid line) (log-rank $p=0.00238)$; (B) Patients with a low lymphocyte count $\leq 1555.2 / \mu \mathrm{l}$ (dotted line) have a significantly worse CSS than patients with a high lymphocyte count $(>1555.2 / \mu \mathrm{l})($ solid line $)(\log$-rank $p=0.0315)$. 
Table 3: Relationships between clinical characteristics and the preoperative lymphocyte count

\begin{tabular}{|c|c|c|c|}
\hline \multirow{3}{*}{ Parameter } & \multicolumn{2}{|c|}{ Lymphocyte count $(/ \mu \mathrm{l})$} & \multirow{3}{*}{$\mathbf{p}$} \\
\hline & $\leq 1555.2$ & $>1555.2$ & \\
\hline & $(n=79)$ & $(n=63)$ & \\
\hline Recurrence & & & 0.004 \\
\hline No & $64(81)$ & $61(97)$ & \\
\hline Yes & $15(19)$ & $2(3)$ & \\
\hline Age (y) & $74.5 \pm 10.7$ & $69.1 \pm 10.3$ & 0.003 \\
\hline Sex & & & 0.130 \\
\hline Male & $40(51)$ & $40(63)$ & \\
\hline Female & $39(49)$ & $23(37)$ & \\
\hline Location & & & 0.177 \\
\hline Right colon & $38(48)$ & $23(37)$ & \\
\hline Left colon & $41(52)$ & $40(63)$ & \\
\hline Differentiation & & & 1.000 \\
\hline Well/Moderately/Pap & $74(94)$ & $60(95)$ & \\
\hline Poor/Muc & $5(6)$ & $3(5)$ & \\
\hline Tumor invasion depth & & & 0.817 \\
\hline $\mathrm{T} 3$ & $66(84)$ & $54(86)$ & \\
\hline $\mathrm{T} 4$ & $13(16)$ & $9(14)$ & \\
\hline Lymphatic involvement & & & 0.036 \\
\hline Negative & $15(19)$ & $22(35)$ & \\
\hline Positive & $64(81)$ & $41(65)$ & \\
\hline Venous involvement & & & 0.573 \\
\hline Negative & $20(25)$ & $19(30)$ & \\
\hline Positive & $59(75)$ & $44(70)$ & \\
\hline Diameter & & & 0.042 \\
\hline$<5 \mathrm{~cm}$ & $29(37)$ & $34(55)$ & \\
\hline$\geq 5 \mathrm{~cm}$ & $49(63)$ & $28(45)$ & \\
\hline CEA & & & 0.576 \\
\hline$<5 \mathrm{ng} / \mathrm{ml}$ & $49(67)$ & $44(72)$ & \\
\hline$\geq 5 \mathrm{ng} / \mathrm{ml}$ & $24(33)$ & $17(28)$ & \\
\hline CA19-9 & & & 0.809 \\
\hline$<37 \mathrm{U} / \mathrm{ml}$ & $61(85)$ & $51(86)$ & \\
\hline$\geq 37 \mathrm{U} / \mathrm{ml}$ & $11(15)$ & $8(14)$ & \\
\hline CEA (ng/ml) & $36.9 \pm 218$ & $6.7 \pm 12.7$ & 0.282 \\
\hline CA19-9 (U/ml) & $38.7 \pm 97.7$ & $21.2 \pm 39.3$ & 0.200 \\
\hline WBC count $\left(\times 10^{2} / \mu \mathrm{l}\right)$ & $61.7 \pm 21.3$ & $72.1 \pm 21.5$ & 0.005 \\
\hline Neutrophil count $\left(\times 10^{2} / \mu \mathrm{l}\right)$ & $45.1 \pm 20.1$ & $44.8 \pm 20.4$ & 0.949 \\
\hline Lymphocyte count $\left(\times 10^{2} / \mu \mathrm{l}\right)$ & $11.4 \pm 2.6$ & $20.6 \pm 4.5$ & $<0.001$ \\
\hline
\end{tabular}




\begin{tabular}{lccc}
\hline & \multicolumn{2}{c}{ Lymphocyte count $(/ \boldsymbol{\mu l})$} & \\
\cline { 2 - 3 } Parameter & $\mathbf{1 5 5 5 . 2}$ & $\mathbf{7 1 5 5 5 . 2}$ & $\mathbf{p}$ \\
\cline { 2 - 3 } & $\mathbf{( n = 7 9 )}$ & $\mathbf{( n = 6 3 )}$ & 0.051 \\
\hline Monocyte count $\left(\times 10^{2} / \mu \mathrm{l}\right)$ & $3.7 \pm 1.8$ & $4.3 \pm 1.6$ & 0.216 \\
Platelet count $\left(\times 10^{4} / \mu \mathrm{l}\right)$ & $26.9 \pm 10.0$ & $29.0 \pm 9.3$ & 0.27 \\
Albumin $(\mathrm{g} / \mathrm{dl})$ & $3.77 \pm 0.58$ & $3.87 \pm 0.54$ & 0.779 \\
Adjuvant chemotherapy & & & \\
Yes & $7(9)$ & $7(11)$ & \\
No & $72(91)$ & $56(89)$ & \\
\hline
\end{tabular}

Table 4: Univariate analysis for recurrence-free survival (RFS)

\begin{tabular}{|c|c|c|c|c|}
\hline \multirow{2}{*}{ Parameter } & & \multicolumn{3}{|c|}{ RFS } \\
\hline & & $\mathbf{p}$ & HR & $95 \%$ CI \\
\hline \multirow[t]{2}{*}{ Age (y) } & $<60$ & & & \\
\hline & $\geq 60$ & 0.51 & 0.56 & $0.10-3.12$ \\
\hline \multirow[t]{2}{*}{ Sex } & Male & & & \\
\hline & Female & 0.14 & 0.4 & $0.12-1.36$ \\
\hline \multirow[t]{2}{*}{ Location } & Right colon & & & \\
\hline & Left colon & 0.047 & 3.26 & $1.02-10.45$ \\
\hline \multirow[t]{2}{*}{ Differentiation } & Well/Moderately/Pap & & & \\
\hline & Poor/Muc & 0.86 & 0.82 & $0.09-7.60$ \\
\hline \multirow[t]{2}{*}{ Tumor invasion depth } & $\mathrm{T} 3$ & & & \\
\hline & $\mathrm{T} 4$ & 0.0053 & 6.71 & $1.76-25.56$ \\
\hline \multirow[t]{2}{*}{ Lymphatic involvement } & Negative & & & \\
\hline & Positive & 0.32 & 2.41 & $0.42-13.85$ \\
\hline \multirow[t]{2}{*}{ Venous involvement } & Negative & & & \\
\hline & Positive & 0.43 & 2.06 & $0.35-12.21$ \\
\hline \multirow[t]{2}{*}{ Diameter } & $<5 \mathrm{~cm}$ & & & \\
\hline & $\geq 5 \mathrm{~cm}$ & 0.31 & 0.52 & $0.15-1.84$ \\
\hline \multirow[t]{2}{*}{ CEA } & $<5 \mathrm{ng} / \mathrm{ml}$ & & & \\
\hline & $\geq 5 \mathrm{ng} / \mathrm{ml}$ & 0.91 & 1.07 & $0.34-3.35$ \\
\hline \multirow[t]{2}{*}{ CA19-9 } & $<37 \mathrm{U} / \mathrm{ml}$ & & & \\
\hline & $\geq 37 \mathrm{U} / \mathrm{ml}$ & 0.075 & 3.67 & $0.88-15.34$ \\
\hline \multirow[t]{2}{*}{ Lymphocyte count } & $\leq 1555.2 / \mu 1$ & & & \\
\hline & $>1555.2 / \mu \mathrm{l}$ & 0.00016 & 0.03 & $0.00-0.18$ \\
\hline \multirow[t]{2}{*}{ PPLR } & $\leq 1.151$ & & & \\
\hline & $>1.151$ & 0.00044 & 0.11 & $0.03-0.38$ \\
\hline
\end{tabular}

PPLR: post/preoperative lymphocyte count ratio. 
Table 5: Multivariate analysis for recurrence-free survival (RFS)

\begin{tabular}{lcccc}
\hline \multirow{2}{*}{ Parameter } & & $\mathbf{p}$ & HR & 95\% CI \\
\cline { 3 - 5 } & & & & \\
\hline Location & Right colon & & & \\
& Left colon & 0.118 & & $0.8-6.3$ \\
Tumor invasion depth & $\mathrm{T} 3$ & & & \\
& $\mathrm{~T} 4$ & 0.00003 & 10.1 & $3.4-29.9$ \\
Lymphocyte count $(/ \mu \mathrm{l})$ & $\leq 1555.2$ & & & \\
& $>1555.2$ & 0.0001 & 0.04 & $0.009-0.22$ \\
PPLR & $\leq 1.151$ & & & \\
& $>1.151$ & 0.0009 & 0.15 & $0.05-0.46$ \\
\hline
\end{tabular}

PPLR: post/preoperative lymphocyte count ratio.

The association between colon cancer and lymphocyte counts has been examined in studies as early as the 1970s, in which a decrease in lymphocyte counts was found in patients with more advanced colon cancer [21]. Additionally, as one of the potential predictive markers, an elevated preoperative NLR was found to be a predictor of recurrence and worse survival after resection of CRC $[17,22,23]$. In the present study, RFS and OS of stage II colon cancer were found to be highly correlated with decreased lymphocyte counts, though preoperative NLR was not found to be an independent prognostic variable for recurrence of stage II colon cancer, as previously reported [23]. Furthermore, lymphocyte number and PPLR were combined, and it was possible to predict recurrence of colon cancer with higher accuracy than with lymphocyte number alone (RFS $(p=0.00238)$ and CSS $(p=0.0315)$ for lymphocyte number alone, RFS $(p<0.0001)$ and CSS $(p=0.00128)$ for lymphocyte number and PPLR together). These data suggest that

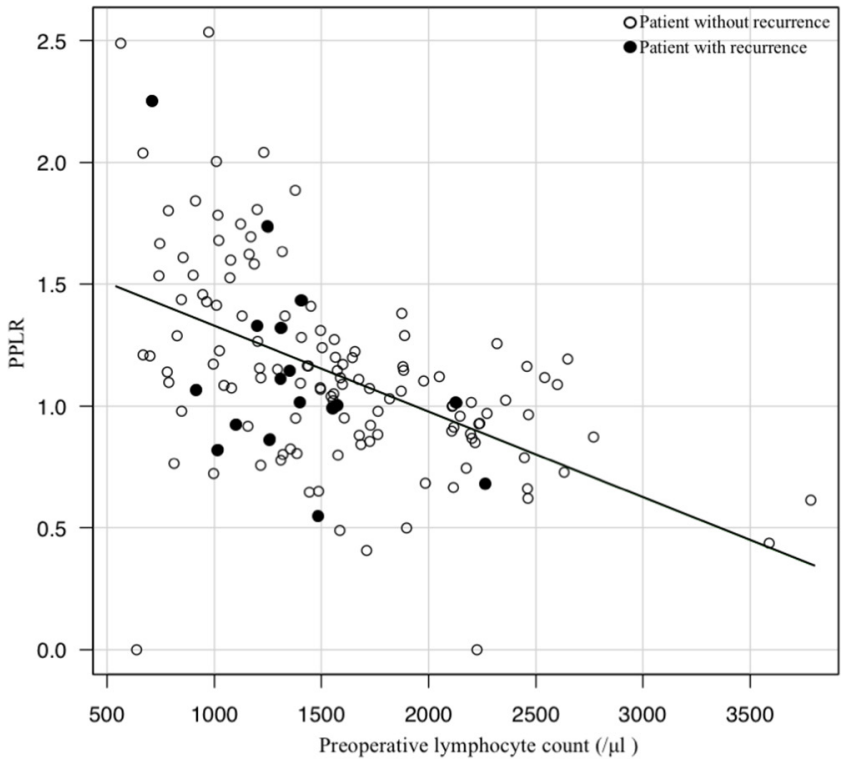

Figure 4: Scatter-plot of the preoperative lymphocyte count and the post/preoperative lymphocyte count ratio (PPLR) There is a significant negative correlation between the preoperative lymphocyte count and the PPLR on Pearson's product moment correlation coefficient analysis $(r=-\mathbf{0 . 5 0 1}, \mathbf{9 5} \% \mathrm{CI}: \mathbf{- 0 . 6 1 5}-\mathbf{0 . 3 6 6}, \boldsymbol{p}<\mathbf{0 . 0 1})$. The group with a low preoperative lymphocyte count and low PPLR has more frequent recurrences (white circle, patient without recurrence; black circle, patient with recurrence). 
patients whose preoperative lymphocyte number and PPLR are both low tend to have recurrence.

The lymphocyte count decrease in patients with recurrent $\mathrm{CRC}$ may be due to the possibility that patients who naturally have a low lymphocyte could more easily develop recurrent colon cancer. As to why PPLR is a predictive marker, it is considered that the lymphocyte counts increase after tumor resection $(1548.0 / \mu$ l before surgery, 1640.7/ $\mu 1$ after surgery, $p=0.046$; data not shown). These data indicate that lymphocytes are accumulated and consumed at the tumor and metastatic foci, as shown in previous reports [24, 25], and/or that tumors inhibit lymphocyte production ability in the bone marrow, presumably through soluble factors including exosomes [26, 27]. Therefore, after successful cancer resection, postoperative lymphocyte counts should increase compared to preoperative lymphocyte counts. Thus, a low PPLR indicates that there could be still remaining tumors or micrometastatic foci.

For patients with a low lymphocyte count and a low PPLR, a better drug treatment would be one that would increase the number of lymphocytes, such as proteinbound polysaccharide kureha (Kureha Corporation, Tokyo, Japan), Z-100 (ZERIA Pharmaceutical Corporation, Tokyo, Japan) [28, 29]. Furthermore, immune-enhancing nutritional supplements may be effective [30, 31]. The advantage of this approach is that lymphocyte counts and PPLR are easy and inexpensive to monitor. In addition, identifying the types of lymphocytes that are reduced would be informative for the development of new drugs and therapeutic approaches. In order to clarify this, further studies using flow cytometry and antibodies for lymphocytes such as $\mathrm{T}$ and $\mathrm{B}$ cells would be needed. In sum, the number of lymphocytes and PPLR could be used in clinical settings to predict the prognosis of patients with colon cancer after curative resection.

In conclusion, the combination of the lymphocyte count and the PPLR appears to be a potential marker for predicting recurrence of stage II colon cancer. Further study is needed to determine whether lymphocyte counts have a direct correlation to recurrence of stage III colon cancer. Since stage IV colon cancer already has metastases to other organs, a study examining the relationship between overall survival/progression-free survival during chemotherapy and the combination of the lymphocyte count and the PPLR would be needed. Additionally, the types of lymphocytes that are reduced also requires further clarification.
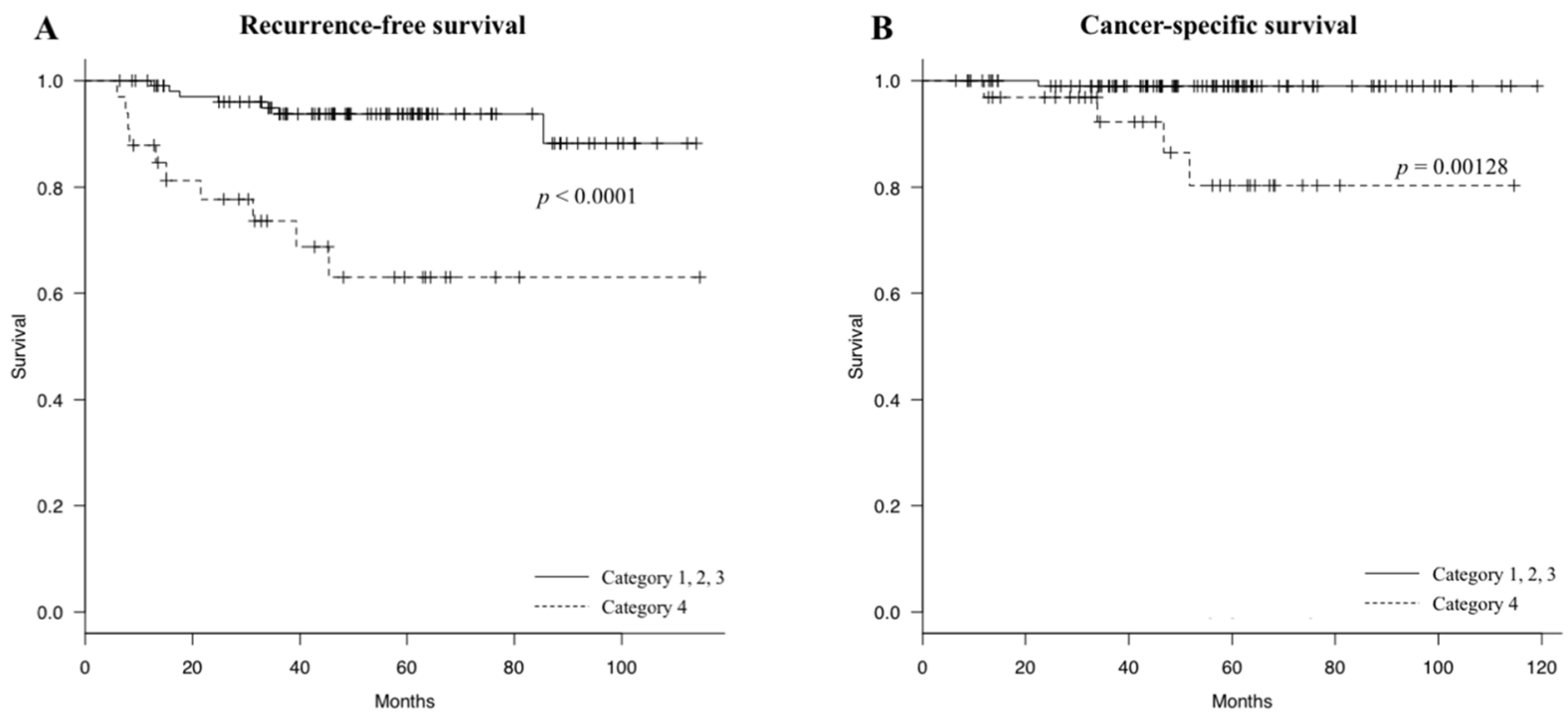

Figure 5: Recurrence-free survival (RFS) curves and cancer-specific survival (CSS) curves categorized by the preoperative lymphocyte count and the post/preoperative lymphocyte count ratio (PPLR) (A) Patients in category 4 (dotted line) show a worse RFS compared to the other categories (solid line) (log-rank $p<0.0001$ ); (B) Patients in category 4 (dotted line) show a worse CSS compared to the other categories (solid line) (log-rank $p=0.00128)$. 


\section{MATERIALS AND METHODS}

\section{Patients and clinical follow-up}

A retrospective review of a database with 142 patients who had undergone curative surgery for histological TNM stage II colon cancer between January 2008 and December 2014 at a single institution (Nippon Medical School Hospital, Bunkyo-ku, Tokyo, Japan) was conducted. Disease stage was established in accordance with the AJCC 7th classification. The exclusion criteria included: emergency surgery (colorectal cancer with intestinal perforation or obstruction), 10 patients; double cancer, 39 patients; period of observation less than 180 days, 18 patients; and incomplete clinicopathological data, 21 patients (Figure 1). Fourteen of 142 patients received adjuvant chemotherapy after surgery, including oral adjuvant uracil and tegafur plus leucovorin (UFT/UZEL) in 11 patients and capecitabine in 3 patients. Follow-up investigations included clinical check-ups, laboratory measurements (including routine blood examinations and cancer-related marker analysis, such as CEA and CA19-9, every 3-6 months), radiological assessment (abdomen and chest computed tomography, every 6-12 months), and colonoscopy (one and three years after the surgery). All patients were followed-up from 6.1 to 116.3 months after surgical treatment. RFS was defined as the interval from radical surgery to recurrence. This study was conducted in accordance with the principles embodied in the Declaration of Helsinki and approved by the ethics committee of Nippon Medical School. (Registration no. 29-07-781).

\section{Clinicopathological data}

All patient-related data were retrieved from the medical record database, including blood test values, some biochemical indicators such as serum albumin levels and serum CEA and CA19-9 levels, as well as demographic information and postoperative pathological results. Preoperative blood laboratory tests were carried out within 30 days before surgery, and postoperative blood laboratory tests were performed between 21 and 90 days after surgery. NLR was defined as the serum absolute neutrophil count divided by the serum absolute lymphocyte count, and PPLR was defined as the postoperative serum absolute lymphocyte count divided by the preoperative lymphocyte count in peripheral blood. NLR and PPLR were calculated for each patient.

\section{Combined use of the preoperative lymphocyte count and the post/preoperative lymphocyte count ratio (PPLR)}

The patients were divided into four categories based on their preoperative lymphocyte count and PPLR.
Patients with a high preoperative lymphocyte count $(>1555.2 / \mu 1)$ and high PPLR $(>1.151)$ were categorized into category $1(\mathrm{n}=11)$. Patients with a high preoperative lymphocyte count and a low PPLR $(>1555.2 / \mu 1, \leq 1.151)$ were categorized into category $2(n=52)$. Patients with a low preoperative lymphocyte count and a high PPLR $(\leq 1555.2 / \mu 1,>1.151)$ were categorized into category 3 (n $=46)$. Patients with a low preoperative lymphocyte count and a low PPLR $(\leq 1555.2 / \mu 1, \leq 1.151)$ were categorized into category $4(\mathrm{n}=33)$.

\section{Statistical analysis}

The chi-squared test or Fisher's exact test were used for categorical variables. Quantitative data are presented as means \pm standard deviation and compared using the Mann-Whitney U test. Pearson's test was used for correlations. Univariate analysis was performed to evaluate clinical characteristics related to RFS. On multivariate Cox regression analysis, the model was adjusted for prognostic clinicopathological factors on univariate analysis. Hazard ratios estimated from the Cox regression analysis are reported as relative risks with corresponding 95\% confidence intervals. Survival curves were prepared using the Kaplan-Meier method and compared by the logrank test. All statistical analyses were performed with EZR (Saitama Medical Center, Jichi Medical University, Saitama Japan), which is a graphical user interface for R (The R Foundation for Statistical Computing, Vienna, Austria). More precisely, it is a modified version of $\mathrm{R}$ commander designed to add statistical functions frequently used in biostatistics [32]. All analyses were two-sided, and a $p$ value of $<0.05$ was considered significant.

\section{Abbreviations}

ROC: receiver operating characteristic; PPLR: post/preoperative lymphocyte count ratio; CA199: carbohydrate antigen 19-9; RFS: recurrence-free survival; CSS: cancer-specific survival; CRC: colorectal cancer; CEA: carcinoembryonic antigen; SIS: systemic inflammation score; LMR: lymphocyte and monocyte ratio; NLR: neutrophil and lymphocyte ratio; PLR: platelet to lymphocyte ratio; PDW: platelet distribution width; EGTM: European Group on Tumor Markers; AUC: area under the curve; $\mathrm{CI}$; confidence interva.

\section{Author contributions}

S.S. and Y.U. designed the research and wrote the main manuscript. S.S. analyzed data from colon cancer patients. S.S., T.Y., and M.K. prepared all figures and tables. Y.Y., G.T., M.H., T.I., K.H., K.T., M.O., and H.K. acquired the data. E.U. helped in interpretingthe results, making critical revisions, and final approval of the article. 


\section{CONFLICTS OF INTEREST}

The authors have declared that no competing interests exist.

\section{FUNDING}

This work was supported by PRIME from the Japan Agency for Medical Research and Development (to Y.U.).

\section{REFERENCES}

1. Arnold M, Sierra MS, Laversanne M, Soerjomataram I, Jemal A, Bray F. Global patterns and trends in colorectal cancer incidence and mortality. Gut. 2017; 66: 683-91. https://doi.org/10.1136/gutjnl-2015-310912.

2. Ajiki W, Tsukuma H, Oshima A; Research Group for Population-based Cancer Registration in Japan. Cancer incidence and incidence rates in Japan in 1999: estimates based on data from 11 population-based cancer registries. Jpn J Clin Oncol. 2004; 34: 352-6. https://doi.org/10.1093/ jjco/hyh056.

3. Shimada Y, Hamaguchi T, Mizusawa J, Saito N, Kanemitsu Y, Takiguchi N, Ohue M, Kato T, Takii Y, Sato T, Tomita N, Yamaguchi S, Akaike M, et al. Randomised phase III trial of adjuvant chemotherapy with oral uracil and tegafur plus leucovorin versus intravenous fluorouracil and levofolinate in patients with stage III colorectal cancer who have undergone Japanese D2/D3 lymph node dissection: final results of JCOG0205. Eur J Cancer. 2014; 50: 2231-40. https://doi.org/10.1016/j.ejca.2014.05.025.

4. Tomasello G, Petrelli F, Ghidini M, Russo A, Passalacqua $\mathrm{R}$, Barni S. FOLFOXIRI plus bevacizumab as conversion therapy for patients with initially unresectable metastatic colorectal cancer: a systematic review and pooled analysis. JAMA Oncol. 2017; 3: e170278. https://doi.org/10.1001/ jamaoncol.2017.0278.

5. Okuno M, Hatano E, Nishino H, Seo S, Taura K, Uemoto S. Does response rate of chemotherapy with molecular target agents correlate with the conversion rate and survival in patients with unresectable colorectal liver metastases?: a systematic review. Eur J Surg Oncol. 2017; 43: 1003-12. https://doi.org/10.1016/j.ejso.2016.08.019.

6. Dahl O, Pfeffer F. Twenty-five years with adjuvant chemotherapy for colon cancer-a continuous evolving concept. Acta Oncol. 2015; 54: 1-4. https://doi.org/10.3109 /0284186X.2014.958533.

7. Bockelman C, Engelmann BE, Kaprio T, Hansen TF, Glimelius B. Risk of recurrence in patients with colon cancer stage II and III: a systematic review and metaanalysis of recent literature. Acta Oncol. 2015; 54: 5-16. https://doi.org/10.3109/0284186X.2014.975839.

8. Andre $\mathrm{T}$, Boni $\mathrm{C}$, Navarro $\mathrm{M}$, Tabernero J, Hickish $\mathrm{T}$, Topham C, Bonetti A, Clingan P, Bridgewater J, Rivera F, de Gramont A. Improved overall survival with oxaliplatin, fluorouracil, and leucovorin as adjuvant treatment in stage II or III colon cancer in the MOSAIC trial. J Clin Oncol. 2009; 27: 3109-16. https://doi.org/10.1200/JCO.2008.20.6771.

9. Ejaz A, Casadaban L, Maker AV. Utilization and impact of adjuvant chemotherapy among patients with resected stage II colon cancer: a multi-institutional analysis. J Surg Res. 2017; 215: 12-20. https://doi.org/10.1016/j.jss.2017.03.017.

10. Fang SH, Efron JE, Berho ME, Wexner SD. Dilemma of stage II colon cancer and decision making for adjuvant chemotherapy. J Am Coll Surg. 2014; 219: 1056-69. https:// doi.org/10.1016/j.jamcollsurg.2014.09.010.

11. Takagawa R, Fujii S, Ohta M, Nagano Y, Kunisaki C, Yamagishi S, Osada S, Ichikawa Y, Shimada H. Preoperative serum carcinoembryonic antigen level as a predictive factor of recurrence after curative resection of colorectal cancer. Ann Surg Oncol. 2008; 15: 3433-9. https://doi.org/10.1245/s10434-008-0168-8.

12. Becerra AZ, Probst CP, Tejani MA, Aquina CT, Gonzalez MG, Hensley BJ, Noyes K, Monson JR, Fleming FJ. Evaluating the prognostic role of elevated preoperative carcinoembryonic antigen levels in colon cancer patients: results from the National Cancer Database. Ann Surg Oncol. 2016; 23: 1554-61. https://doi.org/10.1245/ s10434-015-5014-1.

13. Ceze N, Thibault G, Goujon G, Viguier J, Watier H, Dorval E, Lecomte T. Pre-treatment lymphopenia as a prognostic biomarker in colorectal cancer patients receiving chemotherapy. Cancer Chemother Pharmacol. 2011; 68: 1305-13. https://doi.org/10.1007/s00280-011-1610-3.

14. Ray-Coquard I, Cropet C, Van Glabbeke M, Sebban C, Le Cesne A, Judson I, Tredan O, Verweij J, Biron P, Labidi I, Guastalla JP, Bachelot T, Perol D, et al. Lymphopenia as a prognostic factor for overall survival in advanced carcinomas, sarcomas, and lymphomas. Cancer Res. 2009; 69: 5383-91. https://doi.org/10.1158/0008-5472. CAN-08-3845.

15. Suzuki Y, Okabayashi K, Hasegawa H, Tsuruta M, Shigeta K, Kondo T, Kitagawa Y. Comparison of preoperative inflammation-based prognostic scores in patients with colorectal cancer. Ann Surg. 2016. https://doi.org/10.1097/ SLA.038209R1038209R12115.

16. Shibutani M, Maeda K, Nagahara H, Iseki Y, Ikeya $T$, Hirakawa K. Prognostic significance of the preoperative lymphocyte-to-monocyte ratio in patients with colorectal cancer. Oncol Lett. 2017; 13: 1000-6. https://doi. org/10.3892/ol.2016.5487.

17. Song X, Zhu H, Pei Q, Tan F, Li C, Zhou Z, Zhou Y, Yu N, Li Y, Pei H. Significance of inflammation-based indices in the prognosis of patients with non-metastatic colorectal cancer. Oncotarget. 2017; 8: 45178-89. https:// doi.org/10.18632/oncotarget.16774.

18. You J, Zhang H, Shen Y, Chen C, Liu W, Zheng M, Van Poucke S, Guo G, Huang Z. Impact of platelet to lymphocyte ratio and metabolic syndrome on the prognosis 
of colorectal cancer patients. Onco Targets Ther. 2017; 10: 2199-208. https://doi.org/10.2147/OTT.S132621.

19. Duffy MJ, Lamerz R, Haglund C, Nicolini A, Kalousova M, Holubec L, Sturgeon C. Tumor markers in colorectal cancer, gastric cancer and gastrointestinal stromal cancers: European group on tumor markers 2014 guidelines update. Int J Cancer. 2014; 134: 2513-22. https://doi.org/10.1002/ ijc. 28384 .

20. Smolle MA, Pichler M, Haybaeck J, Gerger A. Genetic markers of recurrence in colorectal cancer. Pharmacogenomics. 2015; 16: 1315-28. https://doi. org/10.2217/pgs.15.83.

21. Kim US, Papatestas AE. Letter: peripheral lymphocyte counts in colonic disease. Lancet. 1974; 2: 462-3.

22. Rashtak S, Ruan X, Druliner BR, Liu H, Therneau T, Mouchli M, Boardman LA. Peripheral neutrophil to lymphocyte ratio improves prognostication in colon cancer. Clin Colorectal Cancer. 2017; 16: 115-23 e3. https://doi. org/10.1016/j.clcc.2017.01.008.

23. Kubo T, Ono S, Ueno H, Shinto E, Yamamoto J, Hase K. Impact of the perioperative neutrophil-to-lymphocyte ratio on the long-term survival following an elective resection of colorectal carcinoma. Int J Colorectal Dis. 2014; 29: 10919. https://doi.org/10.1007/s00384-014-1964-1.

24. Zhong W, Jiang ZY, Zhang L, Huang JH, Wang SJ, Liao C, Cai B, Chen LS, Zhang S, Guo Y, Cao YF, Gao F. Role of $\mathrm{LAP}+\mathrm{CD} 4+\mathrm{T}$ cells in the tumor microenvironment of colorectal cancer. World J Gastroenterol. 2017; 23: 455-63. https://doi.org/10.3748/wjg.v23.i3.455.

25. Mao H, Pan F, Wu Z, Wang Z, Zhou Y, Zhang P, Gou M, Dai G. Colorectal tumors are enriched with regulatory plasmablasts with capacity in suppressing $\mathrm{T}$ cell inflammation. Int Immunopharmacol. 2017; 49: 95-101. https://doi.org/10.1016/j.intimp.2017.05.018.

26. Wen SW, Sceneay J, Lima LG, Wong CS, Becker M, Krumeich S, Lobb RJ, Castillo V, Wong KN, Ellis S, Parker
BS, Moller A. The biodistribution and immune suppressive effects of breast cancer-derived exosomes. Cancer Res. 2016; 76: 6816-27. https://doi.org/10.1158/0008-5472. CAN-16-0868.

27. Yu S, Liu C, Su K, Wang J, Liu Y, Zhang L, Li C, Cong Y, Kimberly R, Grizzle WE, Falkson C, Zhang HG. Tumor exosomes inhibit differentiation of bone marrow dendritic cells. J Immunol. 2007; 178: 6867-75.

28. Yoshitani S, Takashima S. Efficacy of postoperative UFT (Tegafur/Uracil) plus PSK therapies in elderly patients with resected colorectal cancer. Cancer Biother Radiopharm. 2009; 24: 35-40. https://doi.org/10.1089/cbr.2008.0547.

29. Noda K, Ohashi Y, Sugimori H, Ozaki M, Niibe H, Ogita S, Kohno I, Hasegawa K, Kikuchi Y, Takegawa Y, Fujii S, Tanaka K, Ochiai K, et al. Phase III doubleblind randomized trial of radiation therapy for stage IIIb cervical cancer in combination with low- or high-dose Z-100: treatment with immunomodulator, more is not better. Gynecol Oncol. 2006; 101: 455-63. https://doi. org/10.1016/j.ygyno.2005.11.006.

30. Matsuda A, Furukawa K, Takasaki H, Suzuki H, Kan H, Tsuruta H, Shinji S, Tajiri T. Preoperative oral immuneenhancing nutritional supplementation corrects TH1/TH2 imbalance in patients undergoing elective surgery for colorectal cancer. Dis Colon Rectum. 2006; 49: 507-16. https://doi.org/10.1007/s10350-005-0292-5.

31. Caglayan K, Oner I, Gunerhan Y, Ata P, Koksal N, Ozkara $\mathrm{S}$. The impact of preoperative immunonutrition and other nutrition models on tumor infiltrative lymphocytes in colorectal cancer patients. Am J Surg. 2012; 204: 416-21. https://doi.org/10.1016/j.amjsurg.2011.12.018.

32. Kanda Y. Investigation of the freely available easy-touse software 'EZR' for medical statistics. Bone Marrow Transplant. 2013; 48: 452-8. https://doi.org/10.1038/ bmt.2012.244. 